\title{
LINKING A PERFORMANCE MANAGEMENT SYSTEM AND COMPETENCIES: QUALITATIVE RESEARCH
}

pages: $51-67$

\author{
VERONIKA KORENKOVÁ, JÁN ZÁVADSKÝ, MARCIN LIS
}

\begin{abstract}
A B S TR A C T
The main purpose of the paper is to identify the group of indicators that are most widely used in the manufacturing area worldwide, to identify the responsibility and authority for measuring and evaluating business performance, and to create an illustrative competency-based model for a performance management system within a business. The paper covers two areas that are important in the maintenance of sustainable business performance. The first area focuses on a performance management system and its key performance indicators as an important element in every performance management system within a business. The article also presents the theoretical background of the Z-MESOT method, which is applied to define the consistency of these indicators in practice. The second area is dedicated to defining a competency-based model and competences related to the measurement and assessment of performance, which have been extracted from other general competences. This paper presents findings from qualitative research to eliminate the bottlenecks of the Z-MESOT matrix that was transposed into a questionnaire. The questionnaire, as well as structured interviews, helped identify differences in responsibility attributes of the Z-MESOT matrix regarding the size of the researched businesses. The paper offers a list of competences related to the key performance indicators that can be used for following theoretical and practical research.
\end{abstract}

KEY WORDS

competences, Z-MESOT, performance management system, key performance indicators

DOI: 10.2478/emj-2019-0004
Corresponding author:

Veronika Korenková

Matej Bel University, Slovakia e-mail: veronika.korenkova@umb.sk

Ján Závadský

WSB University, Poland e-mail: jan.zavadsky@umb.sk

Marcin Lis

WSB University, Poland e-mail:mlis@wsb.edu.pl

\section{INTRODUCTION}

This paper continues the research started by Závadský, Korenková, Závadská, Kadárová and Tuček (2019). The previous research was based on the most frequently used key performance indicators world- wide. This paper uses the same indicators but also offers a deeper view of theory and practical implications, which is a novelty.

The paper has several research objectives. The first objective is to identify the group of indicators that are most widely used in the manufacturing area worldwide. The second objective is to identify the 
responsibility and authority for measuring and evaluating business performance according to attributes of the Z-MESOT method. The application of the responsibility and authority as a necessary element of competences in the management process enables to interlink the organisation's requirements and the employee's opportunities in a way that permits their development in mutual harmony and to ensure the organisation's competitiveness (Königová \& Hron, 2012; Szczepańska-Woszczyna et al., 2015). The competency-based approach in Performance Management System (PMS) focuses on the behaviour and performance of managers and employees of the organisation as well as on defining essential activities they perform, which is a key to success of the entire organisation (Kubeš et al., 2004 in Lišková and Tomšík, 2013). When applying the competencybased approach to PMS, the identification of competences is a vital step of the company's philosophy.

The third objective is to create an illustrative list of competences of the performance management system within a business, because "competences are connected with the future orientation and a developmental focus as they allow the inclusion of success factors" (Krausert, 2009, p. 185). Traditional job definitions that are replaced by frameworks of competences are supposed to be backwards-oriented because they are derived using job analysis methods (Kalyani, 2016). Competency-based PMSs have been tightly linked to the efforts of companies to create a setting for the empowerment of their employees to increase their competitive advantage, innovation, effectiveness, and performance (Draganidis \& Metzas, 2006), but it has also been related to corporate efforts to utilise a company's internal knowledge (Konigová \& Hron, 2012), personal development (Campion, 2011), and know-how sharing (Vazirani, 2010).

Well-established companies are characterised by the apparent stage of development as perceived by their employees. These organisations consider staff as an asset or a resource rather than variable costs, and it is, therefore, necessary to regard them as human capital (Campion, 2011; Armstrong \& Taylor, 2014). To provide a long-term, sustainable and qualitydriven production within a business, selecting and hiring the right employees is a key. An employee selection procedure has become a complicated process loaded with uncertainty (Dolobac, Mura \& Svec, 2016). Using the resource-based approach to achieve a competitive advantage means perceiving an organisation as a unique set of resources and competences, based on which a strategy for the best possible use of opportunities is defined. According to Königová and Hron (2012), the use of competences in the management process enables to interlink the organisation's requirements and the employee's opportunities in a way that permits their development in mutual harmony, and to ensure the organisation's competitiveness in the market.

The paper is structured as to offer a literature review focused on performance management systems and the competence-based approach in performance management systems, defining the Z-MESOT method from theoretical and practical points of view, analysing the qualitative research finding in the performance management system, and defining the list of competences related to key performance indicators used in sample enterprises.

\section{LITERATURE REVIEW}

\subsection{PERFORMANCE MANAGEMENT SYSTEM}

Flapper, Fortuin and Stook (1996) offered a systematic method for designing a consistent performance management system to be used in practice with the focus on the relations between the performance indicators (PIs). In their view, a consistent performance management system (PMS) meant a system that covered all aspects of performance that are relevant to the existence of an organisation as a whole. The system should equip the management with a quick insight into the performance of their organisation's tasks and the extent of the implementation of organisational objectives. The method consists of three main steps: (1) defining performance indicators, (2) defining relations between performance indicators, and (3) setting target values or ranges of values for performance indicators. Ferreira and Otley (2009) described the structure and operation of performance management systems (PMSs) in more holistically. In general, literature uses three important terms: (1) management control system, (2) performance measurement system (PMeS) and (3) performance management system (PMS). From one point of view, the type of system is irrelevant because performance indicators can be found in each one. In their research, Závadský and Hiadlovský (2014) focused on performance indicators and especially their attributes that need to be defined.

From another perspective, PMS is an excellence model that includes requirements for measurement 
and evaluation of performance efficiency. Several models of the kind are available. Based on the Malcolm Baldridge Award, Evans, Ford, Masterson and Hertz (2012) explored ways to further improve and achieve higher levels of performance. Abdullah, Hamid, Mustafa, Husain, Idris, Suradi and Ismail (2012) offered organisations a conceptual framework for the development of a value-based total performance excellence model (VBTPEM). In the model, the core values of an organisation are used as a strategic component use to achieve total performance excellence. It integrates the intangible parts of performance measurement that have become pivotal for many organisations. The study by Doeleman, Have and Ahaus (2012) focused on the moderating role that leadership plays in the relationship between management control as part of total quality management (TQM) and business excellence aimed at targeted change. The study also indicated that transformational leadership had the most influence on the relationship between the construct of management control and purposive change. In the context of transformational leadership, organisations can be strengthened by implementing a management control system used in combination with a thorough management communication approach. Wang (2012) presented a literature review indicating the lack of an appropriate framework for the assessment of organisational performance (OP) during a crisis. He identified key OP indicators and developed a multidimensional framework for the evaluation of OP during crises. Alfaro-Saiz, Carot-Sierra, Rodriguez-Rodriguez and Jabaloyes-Vivas (2011) described the ways to use information resulting from the application of the EFQM excellence model to analyse perceptions of the organisation held by its members based on their business vision. Heras-Saizarbitoria, Marimon and Casadesús (2012) presented an empirical study focused on the relationships between categories of the EFQM model. Lis and Szczepańska-Woszczyna (2015) linked the organisational performance with the necessity to create individual, long-lasting relationships between the company and the customer. Performance is viewed differently, yet neither of the views on PMS served the starting point of research by Závadský and Hiadlovský (2014), which rather dealt with the homogeneity of any of these performance systems with PIs as their basic element.

\subsection{Position of Competences in a Perfor- mance Management System}

In the literature, terms competence, competency, ability, responsibility and performance can be encountered on a daily basis. It can be argued that these terms are often placed within a more empirical rather than a theoretical framework. With the evolvement of scientific disciplines, including business management, various performance management systems (i.e. Performance Management, Business Performance Management, and Corporate Performance Management), and Human Resources Management, new knowledge has been acquired, contributing to new and convoluted interpretations and understandings of the terms. As some of these definitions are still used interchangeably, extensive and, in many cases, chaotic debates continue on the actual meaning and composition of these new notions.

Various authors (Draganidis \& Mentzas, 2006; Vakola, Soderquist \& Prastacos, 2007; Vazirani, 2010) consider "competence" and "ability" as interchangeable terms. Throughout an employment relationship, an employee executes certain tasks that are beneficial for his/her employer. His/her employment includes specific tasks, duties, authorities and responsibilities. Simultaneously, an employee has to socially mature in terms of his/her practical skills and determination.

Armstrong (2007) referred to competence as an expert's ability and competency expressed in certain anticipated behaviour, or a type of behaviour, which is necessary to reach expected goals through teamwork, communication, team leadership and decisionmaking. Bober (2008) assumed that competence could be literally translated as power or authority. Power is closely linked to responsibility for a specific performance. Vazirani (2010) characterised competence as the minimum standard of work performance, and competency as a description of how to reach certain performance standards for businesses.

In the last six years, competence has been defined as the social and individual maturity of an entity (Porvazník, 2007; Vazirani, 2010). Competences are understood as a set of behaviours or internal qualities of individuals executing their responsibilities. In many cases, the authors refer to it as the internal characteristics of an individual and his/her motivation to undertake necessary efforts. It is assumed by the authors of this article that these preconditions are understood as an ability rather than competence.

It is necessary to proceed to a detailed and unambiguous definition of the issue under the current 
analysis. According to Minárová, a work position is defined by "duties to be executed and powers we need for proper execution and responsibility for using such powers when carrying out a specific duty which can be referred to as a competence" (Minárová, 2014, p. 49). However, a work position is limited by "personal requirements of a candidate occupying a specific work position, i.e. general and expert knowledge, practical and applied abilities, social and personal maturity, which are all referred to as abilities" (Minárová, 2014, p. 49). According to Porvazník (2007, p. 24), this term "clarifies what duties, powers and responsibilities an individual or a group of people (a team or an organisation, an institution or an authority) should have." Competence is understood as all the duties, powers and responsibilities related to a particular work position regardless of who will be in charge of a specific competence. From this point of view, competences form a comprehensive strategy to facilitate the peak employee and organisational performance (Kalyani, 2016; Vazirani, 2010).

Seková et al. (2013) and Manohar (2017) defined competency as an ability to execute duties and powers (authorities) effectively and to take responsibility for one's actions. They perceived the word competency as preparability of the management subjects shareholders, managers and employees - to manage and govern their work, or the work of others to create real added value as the main key to success. The linkage of competences to performance management is that competences indicate what the employee can do or has the ability to do and the performance management system indicates what the employee does. Vakola, Soderquist and Prastacos (2007) added that competences, in contrast to competencies, could be delegated and competency can only be acquired through knowledge and experience.

As mentioned above, it may be assumed that an employee's competency includes his/her abilities and competences. Being able to carry out one's duties and being engaged are the main characteristics of one's ability including the following key assets (or personal characteristics): general and expert (professional) knowledge (1), practical and applied abilities (2), social and personal maturity (3), and self-motivation (4).

Competence relates to certain conditions that have to be respected to execute certain work duties. Therefore, competence consists of duty (1), power or authority (2) and responsibility (3). Excellent performance is achieved by the assignment of work duties, powers and responsibilities to employees that have mixed abilities, knowledge, practical skills, social and personal maturity and self-motivation. Appropriate design of roles and responsibility sets are the key to a successful performance management system.

As all the phases of performance measures include a human factor, professional, practical and social requirements have to be determined for those businesses which have an obligation or are entitled to and liable for a measurement process and business performance evaluation (Moore, Cheng \& Dainty, 2002). The ambiguous and vague definition of competences demonstrable by staff members responsible for measuring and evaluating their company's performance process may result in incoherences and disorganisation. Examples of staff members responsible for measuring and evaluating their company's performance are shareholders, top managers, company auditors, junior managers, members of $t$ the controlling department etc. An employee to whom a competence for measurement process and performance evaluation has been delegated, is solely responsible for the quality of the performance management process (Wagner, 2009).

The predetermined arrangement of competences is a general and key feature of a competence model. According to Vazirani (2010), the majority of competence models include 10 to 12 competences to be classified into various categories. A competence model can be regarded as one of the subsystems of business process management as it creates a relation between activities and their implementors (Sanchez \& Levine, 2009; Manohar, 2017). A competence model is a simplified system of business management, including such elements as business activities or human resources. A competence model can identify real responsibility for the performance of a fundamental management level. In summary, a business competence model aims to define the responsibilities and powers of specific work positions for the execution and implementation of particular activities (Závadský, 2012). Various problems can be solved, and direct consequences can be drawn by active engagement of employees in explicitly defined responsibilities and their acceptance (Wagner, 2009; Verle et al., 2014; Olšovská, Mura \& Švec, 2016). When a company creates its system, it is necessary to tailor it according to certain parameters, such as the size of the company, the production programme, company culture and ways of doing business (Tuček \& Dlabač, 2013). 


\subsection{Z-MESOT METHOD AS A TOOL FOR SYSTEMATIC PERFORMANCE MEASUREMENT AND EVALUATION OF A BUSINESS}

The Z-MESOT framework represents a managerial and systematic approach to measuring and evaluating performance. It is mainly used when assessing the degree of consistency within measurement systems and performance evaluations. The managerial and systematic approach is based on the determina-

Tab. 1. Z-MESOT Matrix tion of the attributes particular to specific indicators used for the measurement and evaluation of business performance. Consistency is usually defined as an agreement or compatibility, especially uniformity among the parts of a complex matter. Ensuring consistency within any system is a guarantee for longterm balance (Závadský et al., 2016). The tool, for which consistency of the performance measurement and evaluation systems is identified, is often referred to as the matrix Z-MESOT, as shown in Tab. 1.

\begin{tabular}{|c|c|c|c|c|c|c|c|}
\hline & & 1 & $\ldots$ & $\mathbf{i}$ & $\ldots$ & n & \\
\hline & & $\begin{array}{l}\text { PERFORMANCE } \\
\text { INDICATOR PI }_{1}\end{array}$ & $\ldots$ & $\begin{array}{l}\text { PERFORMANCE } \\
\text { INDICATOR PI }\end{array}$ & $\ldots$ & $\begin{array}{l}\text { PERFORMANCE } \\
\text { INDICATOR PI }_{\mathrm{N}}\end{array}$ & $\Sigma A_{i}$ \\
\hline F1 & Name of the PI & $1 \vee 0$ & $\cdots$ & $1 \vee 0$ & $\ldots$ & $1 \vee 0$ & $<0, n>$ \\
\hline F2 & $\begin{array}{l}\text { Relation to the business } \\
\text { process }\end{array}$ & $1 \vee 0$ & $\ldots$ & $1 \vee 0$ & $\ldots$ & $1 \vee 0$ & $<0, n>$ \\
\hline F3 & $\begin{array}{l}\text { Relation to the strategic } \\
\text { goal }\end{array}$ & $1 \vee 0$ & $\ldots$ & $1 \vee 0$ & $\ldots$ & $1 \vee 0$ & $<0, n>$ \\
\hline F4 & $\begin{array}{l}\text { Strategic goal (name and } \\
\text { sign of the strategic goal) }\end{array}$ & $1 \vee 0$ & $\ldots$ & $1 \vee 0$ & $\ldots$ & $1 \vee 0$ & $<0, n>$ \\
\hline F5 & $\begin{array}{l}\text { Responsibility for the PI's } \\
\text { definition }\end{array}$ & $1 \vee 0$ & $\ldots$ & $1 \vee 0$ & $\ldots$ & $1 \vee 0$ & $<0, n>$ \\
\hline T1 & $\begin{array}{l}\text { Responsibility for the } \\
\text { target value definition }\end{array}$ & $1 \vee 0$ & $\ldots$ & $1 \vee 0$ & $\ldots$ & $1 \vee 0$ & $<0, n>$ \\
\hline T2 & Unit of the PI & $1 \vee 0$ & $\ldots$ & $1 \vee 0$ & $\ldots$ & $1 \vee 0$ & $<0, \mathrm{n}>$ \\
\hline T3 & $\begin{array}{l}\text { Period defined for the } \\
\text { target value achievement }\end{array}$ & $1 \vee 0$ & $\ldots$ & $1 \vee 0$ & $\ldots$ & $1 \vee 0$ & $<0, n>$ \\
\hline T4 & $\begin{array}{l}\text { Determinants of the target } \\
\text { value definition }\end{array}$ & $1 \vee 0$ & $\ldots$ & $1 \vee 0$ & $\ldots$ & $1 \vee 0$ & $<0, n>$ \\
\hline T5 & Target value (number) & $1 \vee 0$ & $\ldots$ & $1 \vee 0$ & $\ldots$ & $1 \vee 0$ & $<0, \mathrm{n}>$ \\
\hline 11 & $\begin{array}{l}\text { Responsibility for the data } \\
\text { recording }\end{array}$ & $1 \vee 0$ & $\ldots$ & $1 \vee 0$ & $\ldots$ & $1 \vee 0$ & $<0, n>$ \\
\hline 12 & $\begin{array}{l}\text { Frequency of data } \\
\text { recording }\end{array}$ & $1 \vee 0$ & $\ldots$ & $1 \vee 0$ & $\ldots$ & $1 \vee 0$ & $<0, n>$ \\
\hline 13 & Place for data recording & $1 \vee 0$ & $\ldots$ & $1 \vee 0$ & $\ldots$ & $1 \vee 0$ & $<0, \mathrm{n}>$ \\
\hline 14 & Source of data & $1 \vee 0$ & $\ldots$ & $1 \vee 0$ & $\ldots$ & $1 \vee 0$ & $<0, n>$ \\
\hline 15 & Calculation formula & $1 \vee 0$ & $\ldots$ & $1 \vee 0$ & $\ldots$ & $1 \vee 0$ & $<0, n>$ \\
\hline 16 & $\begin{array}{l}\text { Automation of the } \\
\text { calculation } \\
\text { (manually/software) }\end{array}$ & $1 \vee 0$ & $\ldots$ & $1 \vee 0$ & $\ldots$ & $1 \vee 0$ & $<0, n>$ \\
\hline E1 & $\begin{array}{l}\text { Responsibility for the PI's } \\
\text { evaluation }\end{array}$ & $1 \vee 0$ & $\ldots$ & $1 \vee 0$ & $\ldots$ & $1 \vee 0$ & $<0, n>$ \\
\hline E2 & $\begin{array}{l}\text { Frequency of the Pl's } \\
\text { evaluation }\end{array}$ & $1 \vee 0$ & $\ldots$ & $1 \vee 0$ & $\ldots$ & $1 \vee 0$ & $<0, n>$ \\
\hline E3 & $\begin{array}{l}\text { Visualisation of the } \\
\text { achieved performance }\end{array}$ & $1 \vee 0$ & $\cdots$ & $1 \vee 0$ & $\ldots$ & $1 \vee 0$ & $<0, n>$ \\
\hline E4 & $\begin{array}{l}\text { Action in case of a } \\
\text { performance gap }\end{array}$ & $1 \vee 0$ & $\ldots$ & $1 \vee 0$ & $\ldots$ & $1 \vee 0$ & $<0, n>$ \\
\hline E5 & $\begin{array}{l}\text { Warning signal for the } \\
\text { evaluator }\end{array}$ & $1 \vee 0$ & $\ldots$ & $1 \vee 0$ & $\ldots$ & $1 \vee 0$ & $<0, n>$ \\
\hline & $\Sigma A_{j}$ & $<0,21\rangle$ & & $<0,21>$ & & $<0,21>$ & \\
\hline
\end{tabular}

Source: (Závadská \& Korenková, 2017). 
The parameters for measuring the functionality of a system are represented by so-called Performance Indicators (PI). Every Performance Indicator is used to research the functionality of a partial structure or the whole business process. Defining a consistency rate is the basis of systematic characteristics. A proposal for the attributes of performance measurement and evaluation should be in line with a systematic approach to its management. A consistent basis for a performance management system is a model comprising the Z-MESOT matrix. This matrix contains 21 attributes for testing the consistency of a performance management system. From the methodological point of view, it is necessary to differentiate between the attributes by particular patterns even though all the attributes end up being integrated into only one indicator. The Z-MESOT matrix contains 21 performance indicators divided into four groups (F1-F5 - formal attributes, T1-T5 - attributes of the indicator's target value, I1-I6 indicator's measurement, E1-E5 - indicator's evaluation) (Závadská \& Korenková, 2017).

This paper presents the analysis of attributes related to responsibility as a fundamental part of competences listed in the Z-MESOT matrix (Tab. 1) necessary for managers as well as other employees. Regardless of the method of performance measurement and evaluation, every business entity has to execute these activities as part of their business. Závadský and Kovalova (2011, p. 4) assumed that the "implementation of specific activities is always delegated to an individual employee or managers in charge of the outcomes of business processes as well as its stability." The Z-MESOT method supports a systematic approach towards the performance measurement and evaluation considering a competency-based approach. Z-MESOT is interlinked with a competence approach when it comes to those attributes defining responsibility in the business performance measurement and evaluation. The Z-MESOT matrix includes four basic attributes defining responsibility: the responsibility for defining an indicator - attribute F5 (1), the responsibility for defining a target value - attribute T1 (2), the responsibility for performance measurement - attribute I1 (3), and the responsibility for performance evaluation - attribute E1 (4).

Attribute F5 from the Z-MESOT matrix is the first important responsibility attribute. Indicators are usually defined by process owners, level managers or even first-level management. It is highly important to define the responsibility for determining its target value T1. When defining an indicator, it is often recommended to determine its target value as well. It is fundamental to appoint an employee in charge (I1) who will be responsible for monitoring the values at the right periodicity (or at the right time) and the right place. In many cases, the responsibility for an indicator's evaluation (E1) is often connected with the responsibility for defining a target value, i.e. when a manager is supervising his/her own indicators. The responsibility for evaluation is also linked to operative performance evaluation. This is performed by company managers or top management (Závadský, 2005; Závadský \& Hiadlovský, 2014).

\section{QUALITATIVE RESEARCH IN THE SELECTED COMPANIES USING THE Z-MESOT METHOD}

A paper form was used to conduct the study, and qualitative research methods were employed to collect and analyse important data with an emphasis on attributes of the Z-MESOT method related to the responsibility for measuring and evaluating performance.

A qualitative approach was used due to the complexity of the analysed issue. The competence model does not consider or explicitly define the variety of available approaches to measurement and performance evaluation systems related to their effectivity, specific responsibilities and powers. The content of the research is rather complex and, therefore, appropriate methods of qualitative research should be used.

In general, qualitative research is focused mainly on small groups of respondents and, therefore, the research sample was rather limited (only 12 enterprises).

All included companies were small and mediumsized enterprises with foreign shareholders, which had already implemented performance measurements and evaluation systems. Based on the theoretical background, a list of 15 key performance indicators was made. New trends in performance measurement and evaluation highlighted the fact that performance does not only concern the measurement and assessment of financial or quantitative indicators. It is necessary to reflect other fields of business (effectivity, productivity etc.), which can not always be measured by way of financial indicators. Thus, the chosen KPIs include both current financial and non-financial indicators of business performance, such as finance 
and marketing, flexibility, productivity, quality, supplies, production efficiency, defects and failures.

Based on theoretical results and the key performance indicators for business performance (Anand \& Grover, 2015; Lin et al., 2011), the following 15 KPIs were further explored by means of a questionnaire:

KPI1. On-Time Delivery,

KPI2. Manufacturing Cycle Time,

KPI3. Capacity Utilisation Rate,

KPI4. Overall Equipment Effectiveness,

KPI5. Inventory Turnover,

KPI6. Manufacturing Costs as a Percentage of Revenue,

KPI7. Productivity in Revenue per Employee,

KPI8. Earnings Before Tax, Interest, Depreciation and Amortisation EBITDA,

KPI9. Overall Labour Effectiveness,

KPI10. Customer Reject Rate,

KPI11. Defects per Million Opportunities,

KPI12. Suppliers Quality Incoming,

KPI13. Customer Satisfaction,

KPI14. Cash Conversation Cycle (CCC),

KPI15. Total Recordable Health and Safety Incident Rate.

Twelve businesses participated in the analysis of their data, seven of which were classified as large enterprises (public limited companies), and five were medium-sized industry businesses (limited companies). The companies differed considerably in terms of their field of business, e.g. textile, leather and apparel manufacturing, plastics and rubber products manufacturing as well as machinery and equipment manufacturing.

The qualitative approach consisted of several basic phases (Fig. 1). Phase one was named "research conception" because it involved defining the research problem together with its main goal and questions in the form of a structured interview. The purpose of qualitative research was to identify responsibilities and powers when measuring and evaluating business performance to create an illustrative competence model of the performance management system. Within this phase, a questionnaire based on the Z-MESOT method was created. This questionnaire had several functionalities. The questionnaire made it possible to identify a consistency rate of performance measurements and evaluations and also identify "TOP 5 KPIs" of the selected enterprises when measuring and evaluating their business performance. Finally, specific work positions were categorised in terms of the responsibility for defining attributes of the selected KPIs.

Phase two includes generating and collecting the data. As the analysed issue is rather complex and difficult to research, individual structured interviews with managers in charge of performance measurement and evaluation were held. The managers were all running medium-sized and small enterprises in Slovakia. Since the matrix came across as rather complicated when first introduced to participants, three separate meetings were arranged with each company. During the first meeting, managers were acquainted with the basis of the Z-MESOT method, its goals and research methods. The second meeting was dedicated to the analysis of KPI attributes and an open discussion regarding the university's standpoint from a more applied and practical business environment. An agreement on the findings was then concluded at the final meeting, which again served as a basis for this research.

The businesses that took part in the structured interviews came from a wide variety of fields. The first round of interviews was conducted in March 2017 and focused mainly on managers/directors who were responsible for quality management systems, integrated management systems or quality management processes including performance measurements and evaluations. The participants admitted that performance measurements and evaluations were important tools for successful company management. The participants also considered the Z-MESOT method not only as a tool for the identification of the consistency rate but also as a new management style within a business or its departments. For the majority of the businesses analysed, the company performance is seen as an important part of quality management.

Phase three of the qualitative research consists of analytical and interpretational approaches. This type of research is characterised by complex, "thick" and

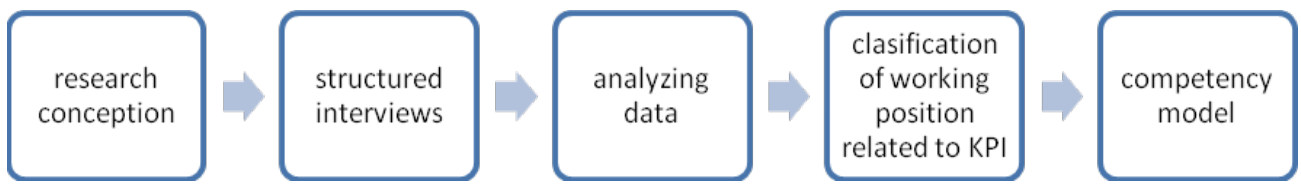

Fig. 1. Qualitative research phases 
disparate data. One data set can be used for all other analyses having a different specialisation (a competence model - the attributes of responsibility, consistency identification - all the attributes).

The last two phases of qualitative analysis consist of description and classification of work positions which are related to the attributes of the Z-MESOT matrix aiming to develop a competence model for performance measurement and evaluation of a business. The main goal was to understand the issue in more detail from a practical, as well as a theoretical, point of view. A practical view is presented by the viewpoint held by managers because the topic of our analysis represents an inseparable part of their daily duties. The research was carried out on the basis of the practical context of the respondents, their experience and perspectives.

\subsection{RESULTS OF THE QUALITATIVE RESEARCH}

The businesses were classified according to the type of production as KPIs were implemented differently in businesses focusing on custom manufacturing in comparison to those who focus on mass production or a combination of these two types. One large and two medium-sized businesses specialised in custom manufacturing accounted for $25 \%$ of analysed businesses. The majority of the businesses, i.e. four large companies and three medium-sized companies, specialised in mass production, which accounts for $58.33 \%$. Two of the larger businesses were considered to be a combination of mass production and custom manufacturing as they focused on customer needs. These companies accounted for $16.67 \%$.

As all of the proposed indicators were tightly linked to the attributes of responsibilities in large businesses (through process owners, as defined by the business information systems), they differed considerably in medium-sized enterprises, as mentioned below in the analysis of particular KPI attributes.

The first KPI was defined by all the large and medium-sized businesses as a key performance indicator. In large businesses, the Logistics Director (the owner of logistics processes) is responsible for defining the indicator and its target value to minimalise, or at least maintain it, in case it is determined by a customer as well as for performance evaluation. Large businesses stated that they were trying to eliminate human failures, which could result in inaccurate KPI measurements or mistakes in performance indicator measurement and evaluation. They assumed that attribute I5 was defined by a specific ERP system which was implemented and used in large businesses. It could, therefore, be assumed that in large businesses, the same person, i.e. the process owner, was responsible for defining the indicator as well as its target value and measurements. However, the same fact could not be applied to medium-sized enterprises. In this instance, it was the Operations Manager who was responsible for defining KPI 1, i.e. for increasing the percentage of customer orders that arrived on time and were tailored to customer requirements. A target value in medium-sized enterprises was determined by the Operations Manager in cooperation with the Logistics Supervisor, whereas in two out of five businesses analysed, it is only a Logistics Supervisor who acted without any cooperation with the Operations Manager. Logistics engineers were in charge of KPI 1 measurements as they collect all the necessary data to be further evaluated, either by a Logistics Supervisor or an Operations Manager.

Manufacturing Cycle Time (hereinafter - KPI 2) was defined by all the analysed large and mediumsized enterprises as a key performance indicator. In large businesses, the attributes of responsibility (F5, T1, E1) were connected with owners of specific processes, to which the indicator belonged. Based on structured interviews, it was found that in four businesses, this indicator was measured and evaluated by the logistics department headed by the Logistics Director, while three businesses had this incorporated in the main production process supervised by their Manufacturing Director. In medium-sized enterprises, this role was delegated to the Operations Managers to reduce the amount of time taken to produce a product and ship it to customers. The indicator's target value was usually determined in cooperation with the Operations Manager and the Production Supervisor. In medium-sized enterprises, such responsibilities were usually delegated to lower management, i.e. the Production Supervisor, which depended on the measured values (recording downtime or time that is needed for retyping manufacturing facilities) in cooperation with production operators. Operations Managers were fully responsible for the evaluation of the indicator in all of the analysed businesses.

KPI 3, i.e. the Capacity Utilisation Rate, was also considered to be a key performance indicator. In all the large businesses we analysed, the owner of the main production process, namely the Manufacturing Director, was in charge of defining the indicator, its target value as well as its evaluation. The Director would also focus on maximising the indicator's value 
to increase the total utilised manufacturing output capacity. In all of the analyses medium-sized businesses, the Operations Manager was responsible for the four attributes of the KPI 3 indicator. In other words, it is possible to talk about the explicit definition of all the responsibility attributes.

Based on the structured interviews, the indicator OEE - KPI 4 was regarded as a key feature only by seven of the mass production businesses. In contrast, this indicator was not considered crucial by custom manufacturing businesses as their production facilities were quite heterogeneous or not identically used (depending on the type of production, to meet customer requirements). As a result, the OEE indicator did not always belong among key performance indicators. For mass production businesses, however, this indicator was one of the most fundamental features. As far as responsibility attributes in large businesses are concerned, three custom manufacturing businesses did evaluate partially the attribute but did not define it explicitly. In the remaining four businesses, the Manufacturing Director was responsible for defining the indicator; while in large businesses, Managers or Chiefs of Departments dealt with the evaluation of the OEE indicator. Two medium-sized enterprises did not have responsibility attributes explicitly defined for the indicator. The remaining three businesses considered the Operations Manager to be responsible for the definition and evaluation of the indicator. The structured interviews showed that specific responsibility attributes were delegated to different employees and, therefore, these were not strictly defined. The target value was not determined only by the Operations Manager, but also by Maintenance or Improvement Supervisors. Besides Maintenance and Improvement Supervisors, there was also the Quality Manager, but only through his/her formal job description. Indicator values were measured by production operators managed by the Production Supervisor. In two of the businesses, it was the Operations Manager who was responsible for measuring the OEE indicator, and one medium-sized respondent indicated a Maintenance and Improvement Supervisor. An inaccurate delegation of responsibility may result in incorrect approaches to its measurement and evaluation. When duties, authorities and responsibilities are not properly defined, this may give rise to numerous arguments among staff on different management levels and eventually lead to a drop in performance of the whole business.

The Inventory Turnover indicator, referred to as KPI 5, was considered a key performance indicator.
In large businesses, responsibility attributes of the Z-MESOT matrix were clearly defined by the owners of the processes, i.e. Logistics Directors. In mediumsized enterprises there was the Operations Manager responsible for defining the Inventory Turns indicator and the Logistics Supervisor who was in charge of determining the indicator's target value as well as its evaluation. The Operations Manager would then evaluate the two processes. There were various people responsible for measuring the Inventory Turns indicator, e.g. Logistics Engineers who managed Logistics Supervisors followed by Production Supervisors and Assembly Coordinators in three cases. However, two of the businesses did not define the I5 attribute. This might be an indicator of inconsistency in defining responsibility attributes of the measurement and performance evaluation systems.

KPI6, i.e. the Manufacturing Costs as a Percentage of Revenue attribute, was regarded as a key performance indicator by all of the analysed large businesses. However, medium-sized enterprises classified it only as a performance indicator despite its regular measurement and evaluation. The owner of financial business processes was fully responsible for its definition, determining its target value as well as its evaluation. In three of the large businesses, this work position was defined as the Purchase and Finance Director, while in the remaining companies he/she was referred to as the Finance Director or the Chief Financial Officer. In the case of medium-sized enterprises, there were various work positions related to responsibility attributes of the KPI 6 indicator. These were General Managers or any other representative within top management who was responsible for measuring and evaluating the given indicator. Their main goal was to focus on the reduction of total manufacturing costs. The whole process involved the Financial Controller who dealt with the finance while the Revenue and Operations Manager focused on planning, budgeting and manufacturing costs. However, the Financial Controller was considered to be fully liable for these processes in medium-sized enterprises.

Productivity in revenue per employee was often referred to as KPI 7 and classified as a financial key performance indicator by all of the analysed large enterprises. In the case of the KPI 6, all of the responsibility attributes were delegated to the Purchase and Finance Director or the Chief Financial Officer. However, in some large businesses, HR Managers and Operations Directors had some participation without being considered owners of financial processes; 
therefore, they were not defined in the E1 attribute. Medium-sized enterprises regarded KPI 7 as a key performance indicator, which was almost identical to KPI 6 when it came to responsibility attributes. The only difference was the HR Coordinator who was responsible for the I1 attribute related to measurement in four businesses. Their main goal was to control and improve productivity in revenue per employee.

Earnings before tax, interest, depreciation and amortisation (EBITDA), hereinafter - KPI 8, were always referred to as a key performance indicator for all of the analysed large and medium-sized enterprises. In large businesses, it was the Chief Financial Officer, as a member of top management, who was responsible for defining the indicator and its target value. However, the Chief Financial Officer did not evaluate the indicator as he/she cooperated closely with the Financial Analysts. In medium-sized enterprises, the General Manager was in charge of the duties, while the target value of EBIDTA was determined by the Financial Controller. A bookkeeper was considered fully liable for measuring KPI 7 even though its evaluation was delegated to the Bookkeeper and the Financial Controller. Close to the KPI 8 was the KPI 14, referred to as Cash Conversation Cycle (CCC), was not considered to be a key performance indicator for the majority of the businesses we analysed, but rather a key indicator for cash-flow. This indicator emphasised possible fluctuations or a discrepancy between payables and obligations. In large businesses, it was the Chief Financial Officer who was responsible for the F5, T1 and E1 attributes. In medium-sized enterprises, the responsibility attributes were identical to other analysed financial indicators (e.g. KPI 8).

KPI 9 represents one of the most modern and the most sophisticated indicators which is supposed to become a highly important and significant metric measuring business performance of human resources in the future. Kronos Corporation from the USA (American Experts at Improving the Performance of People and Business) claimed that effective labour contribution was accomplished when managers could see and manage the three OLE elements availability, performance, and quality (similar to OEE, but applied for HR). A manufacturer can improve shop floor productivity, and therefore the level of profitability, by understanding the interdependency and trade-offs of these three factors and managing them in real time. From among the analysed businesses, only one large corporation imple- mented this indicator, even though it was considered a PI rather than a KPI. Due to inconsistency in performance measurement and evaluation in the case of this indicator, the attributes F5 and T1 were not strictly defined. The HR Manager and the HR Counsellor were responsible for performance measurement and evaluation. Other large and medium-sized enterprises did not measure the indicator or did not even implement it into their practice.

Customer Reject Rate or KPI 10 did not represent a key performance indicator in the analysed large businesses (\% of complaints was only considered as a performance indicator) while three of the mediumsized enterprises consider this indicator as a KPI. When it comes to responsibility attributes for KPI, it was assumed that the three analysed large businesses did not explicitly define the responsibility attributes. The remaining four large businesses defined this indicator vaguely and, therefore, they had to put a lot of effort into determining responsibility. It was discovered that in large businesses, a top management representative (the CEO) or the Chief Marketing Officer was responsible for defining the indicator. Meanwhile, the Quality Director defined the indicator's target value, the Quality Manager or the CRM Manager was in charge of measuring, and the Quality Manager was responsible for its evaluation. In the sample of analysed medium-sized businesses, this indicator was measured and evaluated by all the corporations, three of which considered it a KPI. The General Manager was responsible for its measurement and target value definition while the number of complaints was recorded and administered either by the Quality Manager or the Quality Assurance Engineer with the Quality Manager responsible for its evaluation. The Customer Satisfaction Index (KPI 13), which is related to KPI 10, was regarded as essential and fundamental only by the custom manufacturing businesses as this feature was not considered a key performance indicator in any of the analysed mass production businesses. However, all the enterprises measured and evaluated the indicator. Large and medium-sized mass-production enterprises did not explicitly define responsibility attributes as they were determined only in custom manufacturing businesses. It was the Chief Marketing Officer who was charged with responsibility attributes in large enterprises. In medium-sized enterprises, the responsibility F5 was delegated to the General Manager while responsibilities T1 and E1 were ensured by the Quality Manager with the Quality Assurance Manager in charge of measuring the indicators. There was no 
marketing department in the company hierarchy of medium-sized enterprises operating in the production industry.

The Parts Per Million indicator was seen as a key indicator by all of the analysed medium-sized and large enterprises engaged in mass production. None of the custom manufacturing businesses evaluated or measured the indicator. As this indicator relates to various types of waste, defects and failures, its main purpose is to reduce the amount of these factors within a given process, though, mainly in manufacturing. The Quality Director was responsible for specific responsibility attributes in large enterprises while cooperating with the Quality Manager in the evaluation of the indicator. In medium-sized enterprises, it was the Operations Manager who was considered to be responsible for its evaluation and determining specific steps leading to the improvement or preservation of the required quality. The target value was set by the Operations Manager in cooperation with the Quality Manager. Many other employees were responsible for measuring the indicator, e.g. Production Supervisors, Production Operators, Assembly Coordinators, Process Engineers or Quality Control Engineers as the data were collected from different company departments and summarised by the Operations Manager. In medium-sized enterprises, the data were collected in writing, which might have affected its accuracy.

KPI 12, hereinafter - the Supplier's Quality Incoming, was not considered to be a key performance indicator (but rather an ordinary PI) by any of the large and medium-sized companies. In large businesses, it was the Purchase Director, or the Purchase and Finance Director, who was responsible for defining the indicators. The target value and its evaluation were delegated to the Quality Director as he/she would evaluate suppliers and input quality to increase the value of this particular indicator, but also to ensure the supply from a supplier at the right time, at the right place, in the right quality. In medium-sized enterprises, the General Manager was in charge of defining the indicator while its target value and evaluation is a competence of Quality Manager. The Manager dealt with integral evaluation of the measured data in cooperation with the Quality Assurance Engineer, the Assembly Coordinator or the Procurement Assistant.

The Total Recordable Health and Safety Incident Rate was the last indicator to be analysed. Some of the analysed businesses regarded this rate as a key indicator, while others did not. The large businesses out- sourced this process and, therefore, there was no exact definition of the attributes F5 and T1. It was the Quality Manager or the HR Manager who was responsible for measuring the indicator, the Quality Director or the Integrated Management System Manager dealt with its evaluation. Three medium-sized enterprises did not clearly define the responsibility attributes of the KPI 15, while the remaining two businesses delegated this responsibility to the Quality Manager with the Quality Assurance Engineer being fully liable for measurements and evaluations of the KPI 15 indicator.

The structured interviews presented results of attributes from the Z-MESOT matrix related to responsibilities for the definition KPIs, the determination of target values of indicators, and the measurement and evaluation of the indicators. As a result of the research synthesis, two charts were devised, which included specific work positions in relation to certain attributes of responsibilities for every performance indicator while still respecting the criterium of the company size. The type of production seemed to be important when determining the top 5 KPIs from the proposed indicators (the indicators defined as TOP 5 KPIs in the mass production framework differed considerably from those of custom manufacturing businesses). In regard to the attributes of responsibilities, only minor differences in work positions occurred, mainly due to the company size. The main difference between large and medium-sized businesses was found in the degree and significance of process orientation. All the analysed businesses had detailed process maps at their disposal and defined owners of specific processes. These owners were responsible for "performance indicator management", which was either evaluated by an integrated business management system (Orion) or by using licenced management systems, such as Enterprise Resource Planning (e.g. SAP, Oracle, E-Business Suite, Qlick Sense/View). The effectivity of implementation of an ERP system was generally greater in large businesses. Besides, the ERP implementation was generally considered to be more effective/efficient in large businesses. The analysed medium-sized businesses mainly used Helios Orange or Green, Microsoft Dynamics Nav, Microsoft Dynamix AX, Exact Globe or simple spreadsheet applications, such as MS Excel, to measure and evaluate their business performance indicators. 


\section{DISCUSSION AND PROPOSAL OF THE COMPETENCES RELATED TO KPI}

Aiming to successfully adapt to a rapidly changing business environment, managers need to be proactive. Company managers need to utilise all the potential that exists within the company. Consequently, knowledge of the dramatic environmental changes is not the sole responsibility of the manager but also of employees, so that they can be independent but also contribute to the progress of the whole corporation (Meybodi, 2015). The paradigms of Human Resource Management (HRM) are adapting to changing demands of the working environment and the employees. Competency-based Human Resources are paradigm examples of HRM (Sanchez \& Levine, 2009). HRM research is rarely associated with organisational performance. An integration of these concepts can be found in research conducted by Draganidis and Mentzas (2006), Bober (2008) and Konigova and Hron (2012). Meanwhile, this study aimed to examine the role of HRM and competence modelling to improve organisational performance by explicitly defining all the attributes related to responsibilities.

Based on the analysed indicators, we created nine competence models of performance management systems. The competences were assigned to particular KPIs based on the results of structured interviews with managers of analysed companies. These competence models of performance management systems consist of 15 indicators and work positions, which are defined in specific attributes of the Z-MESOT matrix. There are competences to be recommended (based on a specific indicator) linked to particular responsibilities. Competence models always include ten competences and three basic groups of competencies that are divided into Academic Competencies (general and expert knowledge - group one), Workplace Competencies (practical and applied abilities group two) and Personal Effectiveness Competencies (social and personal maturity - group three) to draw a line between competences and abilities - competencies.

KPI 1 is an indicator of process and supply chain efficiency that measures the number of completed goods or services delivered to customers in time. This indicator helps determine how efficient a company is at meeting the customer requirements or/and agreed deadlines. The competencies in group one should include theoretical as well as practical knowledge of logistics, supply chain fundamentals, operations and management fundamentals, mathematics and statistics. Competencies listed in groups two and three are rather universal for any indicator that would be analysed (KPI 1-KPI 15). Competencies of the group two include e.g. problem solving, decision making, teamwork and collaboration, accountability, customer focus, managerial functions applied in practice, conflict management, analytical thinking, computer skills, stress resiliency, time management etc. Group three consists of integrity, continuous learning, effective communication, active listening, interpersonal skills and emotional intelligence. It can be generalised that KPI 1 has these ten essential competences:

- distribution design, sourcing and management duties,

- global trade compliance (mostly in large companies),

- sourcing and supplier management,

- supply chain continuity planning,

- transportation sourcing and contracts concluding,

- transportation, distribution, logistics tasks,

- distribution requirements planning, inventory management, demand management and its forecasting,

- work with ERP and MRP systems,

- risk management, warehouse management, supply chain synchronisation, strategic sourcing and purchasing, business strategy,

- standards (logistic area), process improvement, lean management, benchmarking.

KPI 2 is the average number of days generally required to process a work order, i.e. the time it would take for a customer's request for a product, standard as well as customised, to reach the appropriate manufacturing facility and be ready for shipping. The first group of abilities includes (in general) theoretical knowledge of logistics, manufacturing, mathematics and statistics, but also practical skillsets. Ten essential competences of KPI 2 are:

- manufacturing process design and development + continuously improving the manufacturing process,

- set up, operate, monitor, control and improve manufacturing processes and schedules,

- coordination of maintenance, installation and repair - optimise manufacturing equipment and systems,

- supply chain continuity planning, 
- $\quad$ logistics - monitor the movement and storage of materials and products in coordination with suppliers, internal systems and customers,

- quality assurance and continuous improvement - ensure product and process meet QMS requirements,

- $\quad$ assure sustainable development and ecological principles of manufacturing,

- $\quad$ work with ERP and MRP systems,

- assurance of Health, Safety and Security employ equipment, practices and procedures,

- $\quad$ standards (ISO...), process improvement, lean management and benchmarking.

KPI 3 is the percentage of capacity utilisation level, which gives insight into the state of the economy, or the state of a company, at any given point in time. Capacity utilisation is an important operational metric for businesses, and also a key economic indicator when applied to aggregate productive capacity. KPI 4 is a widely used performance indicator in manufacturing industries around the world. It is a measure of asset or equipment utilisation. OEE is indicated by the product of the availability index, performance index and the quality index. The first group adopts relevant industry and production knowledge and experience, operations management knowledge, IT skills, project management knowledge, maths and statistics knowledge etc. Ten essential competences of these two KPIs can be generalised:

- coordinate, manage and monitor the working and its progress of production departments in the company,

- review financial statements and data, prepare and control operational budgets, inventory and plan effective strategies,

- $\quad$ improve processes and policies, formulate and implement procedures to maximise output and effectiveness, monitor adherence to rules and procedures,

- monitor and evaluate the performance of the employees, the equipment being used and the entire company,

- ensure the production teams have enough time to manufacture and deliver products for customers as well as general time management,

- responsible for production, procurements and planning of daily operations,

- $\quad$ plan, schedule, review workload and employees to being met on a cost-effective basis,

- $\quad$ work with ERP and MRP systems,

- $\quad$ risk management, warehouse management, supply chain synchronisation, strategic sourcing and purchasing, business strategy, change management and maintenance management

- standards (production area), process improvement, lean management and benchmarking.

KPI 5 is an efficiency indicator of production planning processes and sales/marketing management. This is an important metric and should be regularly evaluated, depending on the industry and finished goods. Inventory holding costs can be a substantial portion of operating/inventory costs and could reduce cash flow. The first group of competencies include e.g. logistics, shipping and warehousing management knowledge and skills, inventory system experience etc. The essential competences of KPI 5 are:

- distribution design, sourcing and management duties,

- $\quad$ schedule shipments and deliveries,

- maintain warehouse inventory, analyse product orders to research the need for keeping certain items in the warehouse, maintain sufficient inventory levels,

- plan the supply chain continuity,

- logistics - monitor the movement and storage of materials and products in coordination with suppliers, internal systems and customers, build a relationship with vendors,

- $\quad$ quality control of inventories, oversee and monitor the availability of stock to reduce shortages,

- manage daily schedules of inventory turns and deliveries of inventories,

- $\quad$ work with ERP and MRP systems,

- employ practices and procedures of warehousing, review inventory needs, support simplification and standardisation of processes to accelerate logistics efficiencies, suggest solutions for improvement, maintain logistic documentation,

- $\quad$ standards (warehousing), process improvement, lean management principles.

KPI 6 is essential for the ability of a business to reduce manufacturing costs, whether it is through adjustments to materials, labour or overheads. Comparisons between plants can give leaders insight into how to load them, whether to substitute raw materials and even renegotiate purchase contracts to reduce costs. KPI 7 can be calculated on several levels: on a company level, department level and even a production-line level. Revenue per employee shows the areas with the lowest and highest ROI. The first group of competencies includes e.g. knowledge of Generally Accepted Accounting Principles (including IFRS), reporting knowledge and skills, contracts law etc. It is 
possible to generalise ten essential competences of these two KPIs:

- preparation of the company's financial statements,

- oversee month-end closing and year-end closing, coordinate and assign staff duties,

- evaluate departmental performance and make adjustments to daily operations when needed to ensure that the department meets overall objectives,

- provide guidance and direction to employees to ensure work is performed efficiently, timely and knowledgeably, use statistics and measure financial indicators related to employees,

- control contracts (financial aspects),

- cooperation with the sales department and operations department,

- financial forecasting and meetings with top management about budgeting and reviewing strategies to meet overall goals and objectives,

- work with ERP and MRP systems,

- risk management, financial management, business strategy,

- standards (accounting, taxes...), work closely with financial institutions and stakeholders.

KPI 8 is the calculation of a business unit or a company's earnings, prior to having any interest payments, tax, depreciation, and amortisation subtracted for any final accounting of income and expenses. EBITDA is typically used as a high-level indication of the current operating profit of a business. KPI 14 is the duration between the purchase of a manufacturing plant or a business unit's inventory, and the collection of payments/accounts receivable for the sale of products that utilise that inventory, typically measured in days. Abilities of the first group of these indicators are identical with the indicators KPI 6 and 7. Ten essential competences of these two KPIs can be generalised:

- preparation of the company's financial statements, reports and special analyses, be a business partner to the CEO,

- oversee month-end closing and year-end closing, coordinate and assigns duties to staff as needed, manage finance, accounting,

- manage and supervise financial accounting, tax and compliance departments with the overall responsibility for hiring and disciplining employees,

- timely, accurate analysis of budgets and financial reports, oversee completion of timely annual audited financial statements,
- provide strategic financial input and leadership on decision-making problems affecting the business,

- cooperation with the sales department and operations department, HR department (new, modified disconnect sales orders, problems...),

- forecast and improve the timeliness and accuracy of cash flows and manage the billing and collections process,

- work with ERP and MRP systems,

- risk management, financial management, business strategy, develop and advise on business development and strategic planning,

- standards (accounting, taxes...), work closely with financial institutions, customers, vendors, auditors and company owners.

KPI 9 has a similar structure as the OEE indicator, but the Overall Labour Effectiveness is divided into its constituent parts Utilisation (direct hours vs attendance hours), Performance (actual speed vs standard speed) and Quality (per cent labour hours lost to rework). The first group mainly consists of knowledge and experience from the field of HRM. Ten competences of the KPI 9 are:

- implement HR programs, identify opportunities for improvement, manage the work related to HR reporting, develop and monitor an annual budget,

- establish HR departmental measurement that supports the accomplishment of the company's strategic goals, prepare periodic reports,

- evaluate departmental performance and adjust daily operations when needed to ensure the department meets overall goals and objectives,

- provide guidance and direction to employees to ensure work is performed,

- coordinate all HR training programs, the implementation of the performance management system including performance development plans,

- cooperate with other departments,

- establish the standard recruiting and hiring practices and procedures, formulate HR policies and objectives,

- work with ERP and MRP systems, manage, develop and maintain human resources information system (employee Intranet...),

- HR management, business strategy, coach and train managers and employees, keep track of the HR legislation,

- manage the process of organisational planning that evaluates structure, job design and person- 
nel forecasting, evaluate plans and change plans, deal with conflicts between employees.

KPI 10 is a quality measure, which reflects the number of completed units rejected or returned by external customers expressed in parts per million. Calculations should include parts reworked by customers. The KPI 13 Customer Satisfaction Index is a universal analytic tool designated for measuring customer satisfaction with a product, service or a company as a whole. It helps to explain the reasons behind a customer's satisfaction or dissatisfaction. The first group of competencies includes CRM knowledge, customer service principles, proficiency in CRM systems etc. Ten essential competences of these two KPIs are:

- develop and implement customer service policies and procedures, define and communicate customer service standards,

- review and assess customer service contracts,

- ensure the necessary resource and tools are available for high-quality customer service delivery,

- review customer complaints, track customer complaint resolution,

- handle complex and escalated customer service issues,

- cooperate with other departments,

- monitor accuracy of reporting and database information, analyse relevant data to determine customer service outputs,

- work with ERP and MRP systems, manage, develop and maintain the information system (employee Intranet, newsletters...),

- maintain CRM Business strategy, keep track of the contracts law, maintain the CRM database, identify and improve quality of service, productivity and profitability,

- co-ordinate and manage customer service project and initiatives.

The KPI 11 is considered as one of the few important Six Sigma metrics. It is the ratio of the number of defects (flaws) in one million opportunities when an item can contain more than one defect. KPI 12 is essential because the quality of materials usually determines the quality of the end products. If the quality of the materials supplied is low, the expenditure for product repairs increases. In an ideal situation, this means an extra cost to the manufacturer. Employers and people in charge have to report incidents - KPI 15. Casualties and life-threatening injuries, such as amputations, have to be reported immediately. Other serious incidents should be reported as soon as the employer has been made aware of the incident. Ten essential competences of these three KPIs can be generalised:

- ensure that the QMS conforms to requirements of the customers, internal procedures, ISO norms and regulators,

- ensure evaluation of and reporting on quality systems,

- manage the monitoring, measurement, review of internal processes, especially those that affect the quality of the product,

- lead a team of quality engineers, inspectors, auditors, analysts, technicians,

- work with customers, employees, contractors, outsourcing companies to develop product requirements, deal with related problems,

- cooperation with other departments, analysis of suppliers, a database of suppliers, assessment of suppliers (material quality, corrective action), + improvements,

- work with ERP and MRP systems, manage, develop and maintain the information system (employee Intranet, newsletters...),

- manage quality, perform root cause analysis and resolve problems,

- monitor the completion of tasks and ensure good performance and record on appropriate systems.

The first group of abilities includes e.g. QMS knowledge and skills, manufacturing and environment management knowledge and skills, experience in Quality Assurance, Lean Manufacturing and skills/ knowledge in mathematics and statistics.

\section{CONCLUSIONS}

In conclusion, we state that the Z-MESOT matrix was used to identify a consistency rate of the selected measurement systems and performance evaluation systems while defining fundamental attributes of indicators and determining responsibility as a key element of competences. Mainly top managers are held directly responsible for defining an indicator. Providing that it is only an operational level of performance and the indicator does not measure a strategic target, it can also be defined by shareholders of the processes or service level management.

Responsibility for defining a target value referred to as T1 (Fig. 1) is closely linked to responsibility for defining an indicator (F5). The general rule says that a person defining an indicator also defines its target value. The target value is important from a point of view of performance evaluation and its determina- 
tion should therefore be delegated to a specific employee. The responsibility for measuring and recording continuous values of indicators (referred to as I1 in Tab. 1) is defined by an employee in charge, who records values within a defined timeframe and at a particular place. The responsibility for the assessment of an indicator (referred to as E1 in Tab. 1) is connected with the attribute T1, i.e. a manager is directly responsible for his/her indicators.

Based on a random selection of large businesses and the obtained results, it may be stated that a person defining an indicator and determining its target value is finally responsible for the evaluation. These responsibilities are not clearly defined in medium-sized businesses or divided among various work positions giving rise to possible conflicts in the workplace. In critical situations, a competent person is required to undertake delegated powers, thus transferring the burden from one work position into another. An explicit definition of specific attributes of particular indicators by means of the Z-MESOT method can help eliminate problems resulting in incorrectly defined responsibilities and powers in the course of measurement and performance evaluation processes.

Performance and measurement responsibilities were explicitly defined in most key performance indicators. Managers positively evaluated a combination of suggested indicators that cover key business performance areas. Competent managers express their opinion that measuring and evaluating performance for them is a necessary tool for successful corporate governance. Overall, the Z-MESOT method positively evaluates the analysed companies. It is not only a useful tool for identifying consistency, but also an instrument that considers methods to represent new enterprise-style management based on the integration of all levels of enterprise performance. For most of the analysed businesses, the performance of an enterprise was an important part of integrated management systems in the practical context.

\section{LITERATURE}

Abdullah, M., Hamid, M. R., Mustafa, Z., Husain, N., Idris, F., Suradi, N. R. M., \& Ismail, W. R. (2012). Valuebased total performance excellence model: A conceptual framework for organisations. Total Quality Management \& Business Excellence, 23(5-6), 557-572.

Alfaro-Saiz, J. J., Carot-Sierra, J. M., Rodríguez-Rodríguez, R., \& Jabaloyes-Vivas, J. M. (2011). Seeking organisational excellence by using the information coming from the EFQM excellence model as starting point: application to a real case. Total Quality Management ¿ Business Excellence, 22(8), 853-868.

Anand, N., \& Grover, N. (2015). Measuring retail Supply chain performance. Theoretical model using key performance indicators (KPIs). Benchmarking: An International Journal, 22(1), 135-166.

Armstrong, M. (2007). Řizení lidských zdrojů. Nejnovejší trendy a postupy. 10. vyd. [Human resource management. Latest trends and practices]. Praha, Czech Republic: Grada Publishing.

Armstrong, M., \& Taylor, S. (2014). Armstrong's handbook of Human Resource Management Practice. 13th edition. London, United Kingdom: Kogan Page Publishers.

Bober, M., et al. (2008). Evaluator Competencies: Standards for the Practice of Evaluation in Organizations. San Francisco, United States: John Wiley \& Sons.

Campion, M. A. et al. (2011). Doing competencies well: best practices in competency modeling. Personnel Psychology, 64, 225-262.

Doeleman, H. J., Have, S., \& Ahaus, K. (2012). The moderating role of leadership in the relationship between management control and business excellence. Total Quality Management \& Business Excellence, 23(5-6), 591-611.

Dolobac, M., Mura, L., \& Svec, M. (2016). Personnel management and the new system of dual education in Slovak Republic. Actual Problems of Economics, 181(7), 282-289.

Draganidis, F., \& Mentzas, G. (2006). Competency based management: a review of systems and approaches. Information Management \& Computer Security, 14(1), 51-64.

Evans, J. R., Ford, M. W., Masterson, S. S., \& Hertz, H. S. (2012). Beyond performance excellence: research insights from Baldrige recipient feedback. Total Quality Management \& Business Excellence, 23(5-6), 489-506.

Flapper, P. S., Fortuin, L., \& Stoop, P. (1996) Towards consistent performance management systems. International Journal of Operations \& Production Management, 16(7), 27-37.

Ferreira, A., \& Otley, D. (2009). The design and use of performance management systems: An extended framework for analysis. Management Accounting Research, 20(4), 263-282.

Kalyani, M. (2016). Competency Mapping process in current scenario: A need for sustainable growth. International Journal of Research in Humanities and Social Studies, 3(3), 18-28.

Heras-Saizarbitoria, I., Marimón, F., \& Casadesús, M. (2012). An empirical study of the relationships within the categories of the EFQM model. Total Quality Management \& Business Excellence, 23(5-6), 523-540.

Kaplan, R. S., \& Norton, D. P. (1996). Translating Strategy Into Action: The Balanced Scorecard. Boston, United States: Harvard Business School Press.

Kolibáčová, J. (2014). The relationship between competency and performance. Acta Universitatis Agriculturae et Silviculturae Mendelianae Brunensis, 62(6), 13151327. 
Königová, M., \& Hron, J. (2012). Methodology for the identification of managerial competencies in knowledge-based organizations. Agricultural Economics, 58(8), 347-353.

Krausert, A. (2009). Performance Management for Different Employee Groups: A contribution to Employment Systems Theory. Heidelberg, Germany: Physica-Verlag Heidelberg.

Lin, G., Shen, G. Q., Sun, M., \& Kelly, J. (2011). Identification of Key Performance Indicators for Measuring the Performance of Value Management Studies in Construction. Journal of Construction Engineering and Management, 137(9), 698-706.

Lis, M., \& Szczepańska-Woszczyna, K. (2015). Managing customer relations: The use of CRM system by services company. Proceedings of the 11th International Conference on Strategic Management and Its Support by Information Systems. SMSIS.

Lišková, S., \& Tomšík, P. (2013). Competency-based approach to human resources management. Agricultural Economics, 59(11), 496-504.

Manohar, A. G. (2017). Competency mapping - readiness of organizations to go in for competency mapping with reference to automobile industries in Nashik industrial area. International Educational Scientific Research Journal, 3(2), 1-5.

Meybodi, M. Z. (2015). Consistency of strategic and tactical benchmarking performance measures. A perspective on managerial positions and organizational size. Benchmarking: An International Journal, 22(6), 1019-1032.

Minárová, M. (2014). Emocionálna inteligencia ako súčast' kompetentnosti manažéra. [Emotional intelligence as a part of the manager's competency]. Banská Bystrica, Slovakia: Belianum.

Moore, D. R., Cheng, M., \& Dainty, A. R. J., (2002). Competence, competency and competencies: performance evaluation in organizations. Work Study, 51(6), 314319.

Olšovská, A., Mura, L., \& Švec, M. (2016). Personnel management in Slovakia: An explanation of the latent issues. Polish Journal of Management Studies, 13(2), 110-120.

Porvazník, J. (2007). Celostní management: Piliere kompetentnosti $v$ manažmente. [Overall management: Pillars of competency in management]. Bratislava, Slovakia: Bratislavská vysoká škola práva.

Porvazník, J., et al. (2013). Celostná manažérska kompetentnost' - potreba, prístupy a metódy jej ohodnocovania. [Overall managerial competency - need, approach, methods its evaluation]. Zborník vedeckých prác z vedeckého seminára. Bratislava, Slovakia: EKONÓM.

Sanchez, J. I., \& Levine, E. L. (2009). What is (or should be) the difference between competency modeling and traditional job analysis? Human Resource Management Review, 19, 53-63.

Seková, M., et al. (2013). Manažment II ludia v organizácii a organizačná kultúra. [Management II. People in organization and their organizational culture]. Bratislava, Slovakia: Iura Edition.
Szczepańska-Woszczyna, K., Dacko-Pikiewicz, Z., \& Lis, M. (2015). Responsible leadership: a real need or transient curiosity. Procedia Social and Behavioral Sciences, 213, 546-551.

Tuček, D., \& Dlabač, J. (2013). Competence Management in Industrial Engineering Departments in the Czech Republic. Proceedings of the European Conference on Knowledge Management, 2, 722-731.

Tučková, Z., \& Tuček, D. (2011). Necessity of it and sw support for business process management. International Journal of Mathematics and Comuputer in Simulation, 15(1), 45-52.

Vakola, M., Soderquist, K. E., \& Prastacos, G. P. (2007). Competency management in support of organizational change. International Journal of Manpower, 28(3-4), 260-275.

Vazirani, N. (2010). Competencies and Competency Model - A brief overview of its Development and Application. SIES Journal of Management, 7(1), 121-131.

Verle, K., et al. (2014). Managerial competencies and organizational structures. Industrial Management, 114(6), 922-935.

Wagner, J. (2009). Meření výkonnosti. Jak měřit, vyhodnocovat' a využivat' informace o podnikové výkonnosti. [Performance evaluation. How to measure, evaluate and use information about company's performance]. Praha, Czech Republic: Grada Publishing.

Wang, W. T. (2012). Evaluating organisational performance during crises: A multi-dimensional framework. Total Quality Management \& Business Excellence, 23(5-6), 673-688

Závadská, Z., \& Korenková, V. (2017). Procesný manažment: teória a prax [Process management: theory and the practice]. Bratislava, Slovakia: Wolters Kulwer.

Závadský, J. (2005). Riadenie výkonnosti podnikových procesov. Banská Bystrica, Slovakia: EF UMB.

Závadský, J., \& Koval'ová, M. (2011). Operatívnaa strategická výkonnost' podnikových procesov [Operational strategic performance of business processes]. Bratislava, Slovakia: Slovenský komitét pre vedecké riadenie ZSVTS.

Závadský, J. (2012). Aplikácia procesného prístupu pri personálnom audite. [Application of the process approach to the personal audit]. Procesný manažér, $7(2), 15-22$.

Závadský, J., Korenková, V., Závadská, Z., Kadárová, J., \& Tuček, D. (2019). Competences in the quality management system evaluation based on the most worldwide used key performance indicators. Quality Access to Success, 20(169), 29-41.

Závadský, J., \& Hiadlovský, V. (2014). The consistency of performance management system based on attributes of the performance indicators: An empirical study. Quality, Innovation, Prosperity, 18(1), 93-105.

Závadský, J., Závadská Z., Veselovská, L., \& SzczepańskaWoszczyna, K. (2016). Consistency of the performance management system and its quantification using the Z-MESOT framework. International Journal for Quality Research, 10(4), 665-684. 